\title{
Transient hypoglycemia as a rare cause of recurring transient loss of consciousness: a case report
}

\author{
Michael Wester ${ }^{1}$ (1), Tanja Bergmann², Martina Müller-Schilling ${ }^{2}$, Lars S. Maier ${ }^{1}$ and Samuel T. Sossalla ${ }^{*}$
}

\begin{abstract}
Background: Syncopes and transient loss of consciousness affect a large number of patients. Determining the underlying mechanism of a syncope is key to effectively treating and preventing future events. However, given the broad differential diagnosis of transient loss of consciousness, it can be challenging to determine the exact etiology.

Case presentation: This case presents a 42-year-old Caucasian female patient with recurrent transient loss of consciousness due to a hitherto undiagnosed impaired glucose tolerance and hyperinsulinism. The patient had been thoroughly tested for all typical causes of syncope without finding any causal explanation. An oral glucose tolerance test confirmed rapidly dropping blood glucose levels associated with rapidly fading consciousness as the underlying cause of transient loss of consciousness. Further diagnostic workup revealed that the patient suffered from impaired glucose tolerance and subsequent hyperinsulinism without overt diabetes mellitus. Nutritional counseling including reduction of glucose intake and frequently eating smaller meal portions led to a significant reduction in the frequency of transient loss of consciousness and overall improvement in quality of life.
\end{abstract}

Conclusions: The current European Society of Cardiology (ESC) guideline on syncope does not list hypoglycemia as a cause of transient loss of consciousness. However, this case report stresses that metabolic dysregulation can indeed lead to self-limited transient loss of consciousness. Thus, in the case of recurrent syncope with an unclear underlying mechanism, physicians should consider transient hypoglycemia and metabolic workup as a possible differential diagnosis.

Keywords: Syncope, Hypoglycemia, Transient loss of consciousness

\section{Background}

Transient loss of consciousness (TLOC) is a state of real or apparent loss of consciousness with loss of awareness, amnesia for the period of unconsciousness, abnormal motor control, loss of responsiveness, and short duration [1]. TLOC can be grouped into TLOC due to head trauma and nontraumatic TLOC, which includes epileptic seizures, psychogenic causes, and rare causes

*Correspondence: Samuel.sossalla@ukr.de

${ }^{1}$ Department of Internal Medicine II, University Medical Center Regensburg, Franz-Josef-Strauß-Allee 11, 93053 Regensburg, Germany

Full list of author information is available at the end of the article (for example subclavian steal syndrome, subarachnoid hemorrhage), and syncope [1]. Syncopes are defined as self-limited TLOC due to cerebral hypoperfusion [1]. Syncopes represent a highly relevant disorder due to their high lifetime prevalence and deleterious effect on quality of life [1]. Finding and effectively treating the underlying cause of syncopes or TLOC can be challenging due to the many shared clinical features with other disorders. The current European Society of Cardiology (ESC) guideline on syncope presents a thorough differential diagnosis paired with etiological explanations [1]. However, metabolic disorders are only acknowledged as causing persistent and not self-limiting loss of consciousness. In this original author(s) and the source, provide a link to the Creative Commons licence, and indicate if changes were made. The images or other third party material in this article are included in the article's Creative Commons licence, unless indicated otherwise in a credit line to the material. If material is not included in the article's Creative Commons licence and your intended use is not permitted by statutory regulation or exceeds the permitted use, you will need to obtain permission directly from the copyright holder. To view a copy of this licence, visit http://creativecommons.org/licenses/by/4.0/. The Creative Commons Public Domain Dedication waiver (http://creativeco mmons.org/publicdomain/zero/1.0/) applies to the data made available in this article, unless otherwise stated in a credit line to the data. 
case, we present a 42-year-old female patient who suffered from recurrent TLOC labeled as syncopes. Despite extensive workup, no cardiac cause could be determined. In contrast, reactive hyperinsulinism was found to cause real TLOC.

\section{Case presentation}

The 42-year-old Caucasian female patient was hospitalized for further evaluation because frequent TLOC in recent weeks had resulted in drastically reduced quality of life and potentially harmful incidents. TLOC had started appearing 11 months earlier (see "Timeline"), right after she had been hospitalized for a herpes zoster oticus infection with involvement of the vestibular nerve. Ten months earlier, she had experienced three symptomatic hypertensive emergencies with headaches and impaired vision. She had been prescribed $2.5 \mathrm{mg}$ bisoprolol daily; however, compliance was poor, as she reported significant fatigue as a side effect. The patient reported recurrent TLOC especially during light exercise such as walking. In some instances, prodromes such as dizziness and sweating preceded TLOC; other times they occurred suddenly, leading to falls including serious injury. Dyspnea or angina pectoris-like symptoms were not present.

During presentation, we initially took a detailed history and were able to establish that she indeed suffered from TLOC during these episodes. She also reported longlasting psychosocial distress as she and her partner had been suffering from unintended childlessness. This had fortunately been resolved when they adopted a child 13 months ago.

The physical examination did not show any abnormalities. Height was $174 \mathrm{~cm}$, weight $64 \mathrm{~kg}$, body mass index (BMI) $21.1 \mathrm{~kg} / \mathrm{m}^{2}$. Heart rate was regular and palpable symmetrically in all extremities (67 beats per minute), and blood pressure was $130 / 75 \mathrm{mmHg}$, with no heart murmurs, normal auscultation of the lungs, and no peripheral edema. The abdominal examination revealed no masses and no tenderness.

Recommended basal evaluation of syncopes and TLOC including history, physical examination, electrocardiography (ECG), blood pressure measurements, and orthostatic testing did not yield any pathological findings.

We focused on further evaluating a potential cardiac cause of TLOC. A treadmill cardiac stress test showed normal physical fitness, no arrhythmias, normal blood pressure and heart rate response, and the absence of relevant ST changes. A 24-hour Holter ECG revealed no pathological findings. To account for rare causes of syncopes, Brugada syndrome was ruled out by performing an ajmaline test. Echocardiography showed normal ejection fraction and no valvular dysfunction or other structural disease. No hint of arrhythmogenic right ventricular cardiomyopathy could be detected in cardiac magnetic resonance imaging (MRI). Urinary levels of catecholamines and their metabolites were normal.

Upon repeated history-taking about preceding situations and potential triggers, we could elaborate on an association with the intake of carbohydrate-rich foods. The patient reported that the TLOC followed carbohydrate-rich meals by approximately 1-2 hours. She had already intuitively changed her diet by abstaining from carbohydrate-rich meals. To evaluate the association with meals, we performed an oral glucose tolerance test. One hundred and eighty minutes after ingestion of $75 \mathrm{~g}$ of glucose, the serum glucose level dropped to $39 \mathrm{mg} /$ dL (see Fig. 1), which induced the same aura symptoms that were familiar to the patient from her previous TLOC with dizziness and rapidly fading consciousness. To prevent complete loss of consciousness, glucose was injected intravenously. Taken together, this provocation test and the detailed medical history proved the hypoglycemic etiology. We therefore established the diagnosis of a pathological glucose tolerance and hyperinsulinism resulting in hypoglycemia and TLOC.

Magnetic resonance imaging (MRI) showed a normal pancreas. A 72-hour-fasting glucose test had been performed and insulinoma had been ruled out. Insulinlike growth factor 1 (IGF-1) levels were normal. Cortisol showed normal levels in serial testing throughout the day. There was no hint of adrenal insufficiency, with normal morning cortisol of $16.2 \mu \mathrm{g} / \mathrm{dL}$. No insulin antibodies were measurable. Noninsulinoma pancreatogenous hypoglycemia syndrome (NIPHS) is a very rare disease causing postprandial hypoglycemia. Testing includes stimulation of pancreatic $\beta$-cells by invasive calcium administration, [2] which was not performed in our patient. Given the relief of symptoms after lifestyle and dietary changes, further invasive testing to distinguish prediabetes from NIPHS was not performed. We recommended primarily dietary changes including frequent small meals to reduce the frequency of hypoglycemic episodes and avoidance of carbohydrate-rich meals as treatment. We discontinued the $\beta$-blocker therapy to avoid interference with glycogenolysis. If symptoms persisted, an off-label metformin therapy for the treatment of her pathological glucose resistance or a treatment test with acarbose, which delays hydrolysis of ingested complex carbohydrates and reduces postprandial glucose and insulin peaks, was suggested. At a follow-up consultation 3 months later, the patient reported no further TLOC after the suggested dietary changes, which led to a markedly improved quality of life. 


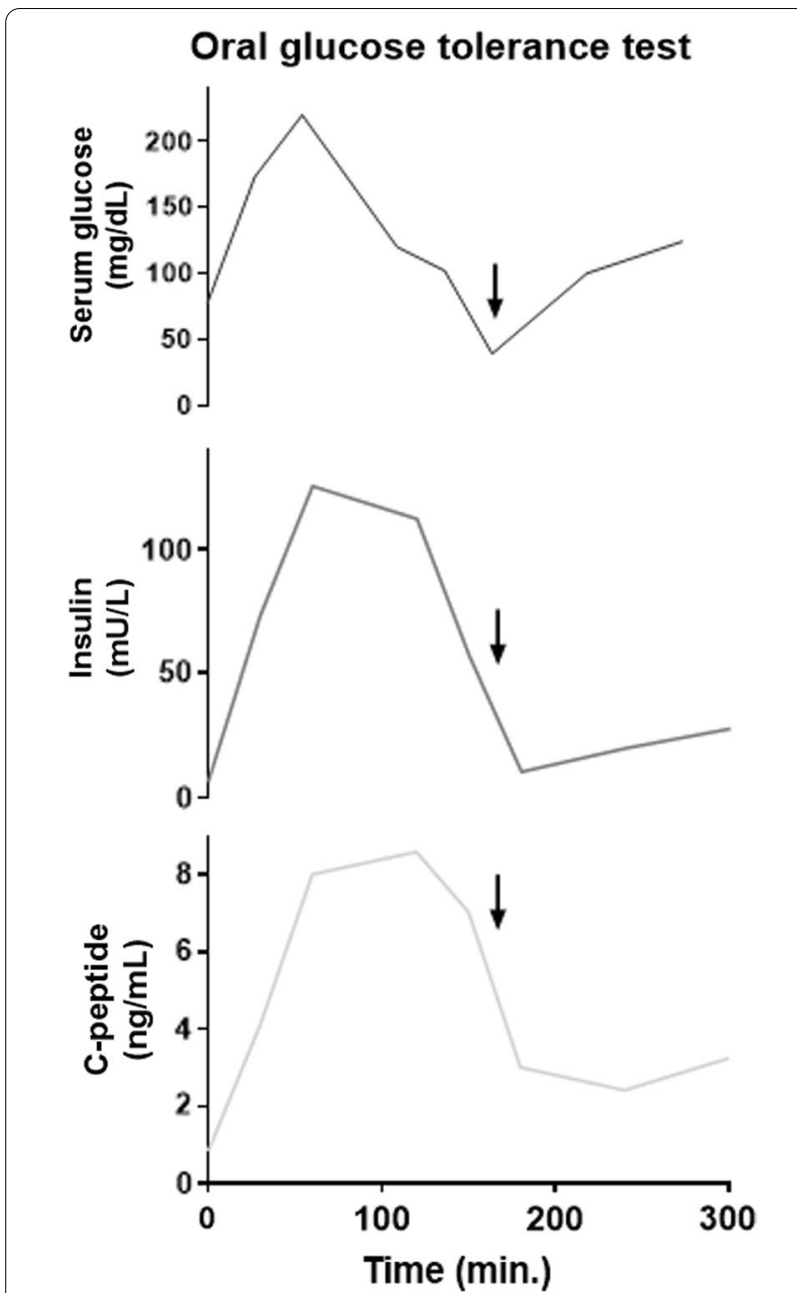

Fig. 1 Values of serum glucose, insulin, and C-peptide during the oral glucose tolerance test after ingestion of $75 \mathrm{~g}$ glucose. Arrow indicates onset of symptoms of presyncope and administration of intravenous glucose to prevent loss of consciousness.

\section{Discussion}

Determining the cause of syncopes and TLOC can be challenging given the broad differential diagnosis. However, identification of the underlying mechanism is crucial to provide optimal treatment and thereby reduce the rate of hospitalization to improve quality of life [3, 4]. Lifetime prevalence of at least one syncope reaches almost 50\% [1]. The most common cause of syncopes is reflex syncope, causing about $20 \%$ of all syncopes, followed by cardiac and orthostatic syncopes, each accounting for about $10 \%$ of all syncopes [3]. However, in more than one third of all patients, no clear etiology can be identified [3,5]. The current ESC guidelines list metabolic disorders including hypoglycemia as a possible false diagnosis for syncope, stating that metabolic changes produce impairment of consciousness instead of loss thereof and produce a much longer duration than the typically short TLOC in syncope [3]. Contrary to this statement, we hereby report that hypoglycemia can indeed lead to a short, self-limiting loss of consciousness, hence perfectly imitating a syncope.

In this case, the differential diagnosis was complicated as the patient was suffering from various different conditions that may also cause TLOC, dizziness, or vertigo (for a summary of differential diagnosis and rule-out criteria in this patient, see Table 1). These include herpes zoster infection with involvement of the vestibular nerve [6], psychogenic non-epileptic seizures [7], hypertensive emergencies [8], and histamine intolerance [9]. Cardiac syncopes represent a common etiology of TLOC and can be caused by potentially life-threatening pathologies [3]. Intensive electrophysiological and imaging studies to reveal structural diseases could rule out a cardiac cause for the syncopes.

Loss of consciousness due to hypoglycemia occurs almost exclusively in older, long-term diabetic patients,

Table 1 Differential diagnoses in our patient showing possible symptoms of the different pathologies that can cause or mimic transient loss of consciousness or syncopes

\begin{tabular}{|c|c|c|}
\hline Differential diagnosis & Possible symptoms & Rule-out criteria \\
\hline Herpes zoster oticus & Vertigo & $\begin{array}{l}\text { Patient could clearly differentiate between the vertigo and the } \\
\text { syncopes }\end{array}$ \\
\hline Hypertensive emergency & Dizziness, impaired vision, headaches & No loss of consciousness during hypertensive episodes \\
\hline Psychogenic non-epileptic seizure & Unintended childlessness as a stressor & Syncopes occurred after stressor had been relieved \\
\hline Histamine intolerance & Flush symptoms (heat, sweating, dizziness) & Complete avoidance of histamine-rich food for more than 1 year \\
\hline Cardiac syncope & Syncope with or without prodromes & $\begin{array}{l}\text { No structural heart disease detected in echocardiography or magnetic } \\
\text { resonance imaging; normal electrocardiogram and normal treadmill } \\
\text { test, no pathological ajmaline test, no arrhythmias in telemetric } \\
\text { monitoring }\end{array}$ \\
\hline
\end{tabular}


especially in combination with antidiabetic medication such as sulfonylurea or insulin [10-12]. Despite still being under debate, reactive hypoglycemia after ingestion of especially carbohydrate-rich food due to increased peripheral insulin resistance and disturbed insulin secretion has been suggested in prediabetes [13, 14]. In conclusion, given its high prevalence, prediabetes and subsequent dysregulation of insulin secretion causing transient hypoglycemia is the most likely cause of the TLOC in our patient. As TLOC sometimes occurred suddenly without any prior aura, the use of a device for continuous real-time glucose monitoring could be advised to further improve quality of life by preventing harmful accidents.

\section{Conclusions}

In summary, the case of this 42-year-old female patient shows the complexity and difficulties of the workup in patients presenting with recurrent syncope. Hypoglycemic episodes in the absence of manifest diabetes can be a rare differential diagnosis for syncopes and should be considered in patients without conclusive workup. Hypoglycemia usually produces prolonged loss of consciousness. To our knowledge, this is the first case describing transient, self-limiting hypoglycemia as a cause for TLOC. This case stresses the importance of thorough history-taking and metabolic workup in patients presenting with syncopes or TLOC.

\section{Appendix}

\section{Timeline: Organized timeline of the patient's symptoms and treatments}

\begin{tabular}{ll}
\hline Time & Events \\
\hline 12 months prior to presentation & $\begin{array}{c}\text { A herpes zoster oticus infection } \\
\text { caused strong vertigo } \\
\text { Three singular hypertensive emer- } \\
\text { gencies led to dizziness, vertigo, } \\
\text { and impaired vision } \\
11 \text { months prior to presentation } \\
\text { Attacks of transient loss of con- } \\
\text { sciousness (TLOC) started to occur }\end{array}$ \\
$\begin{array}{c}\text { Ambulant testing for cardiogenic } \\
\text { syncopes including electrocardi- } \\
\text { ography and echocardiography } \\
\text { showed normal results }\end{array}$ \\
$\begin{array}{c}\text { Frequency of TLOC increased to } \\
\text { several times per week, causing } \\
\text { a drastic impairment of quality } \\
\text { of life }\end{array}$ \\
\hline
\end{tabular}

\begin{tabular}{ll}
\hline Time & Events \\
\hline Clinical presentation & Rule-out of cardiogenic causes for \\
& TLOC; transient hypoglycemia \\
& after glucose ingestion due to \\
& hyperinsulinism established as \\
& cause of TLOC; change of diet \\
& suggested \\
3 months after clinical presenta- & No further TLOC after change of diet \\
tion & to 4-5 small meals throughout \\
& the day \\
\hline
\end{tabular}

Abbreviations

ECG: Electrocardiogram; MRI: Magnetic resonance imaging; NIPHS: Noninsulinoma pancreatogenous hypoglycemia syndrome; TLOC: Transient loss of consciousness.

Acknowledgements

Not applicable.

\section{Authors' contributions}

MW drafted the manuscript. TB contributed to the acquisition of the clinical data. MMS, LSM, and STS provided a detailed review of the content and structure of the manuscript. All of the authors read and approved the final manuscript.

\section{Funding}

Open Access funding enabled and organized by Projekt DEAL.

Availability of data and materials

Not applicable.

\section{Declarations}

Ethics approval and consent to participate

Not applicable.

\section{Consent for publication}

Written informed consent was obtained from the patient for publication of this case report and any accompanying images. A copy of the written consent is available for review by the Editor-in-Chief of this journal.

\section{Competing interests}

The authors have no conflicts of interest to declare.

\section{Author details}

${ }^{1}$ Department of Internal Medicine II, University Medical Center Regensburg, Franz-Josef-Strauß-Allee 11, 93053 Regensburg, Germany. ${ }^{2}$ Department of Internal Medicine I, University Medical Center Regensburg, Franz-Josef-Strauß-Allee 11, 93053 Regensburg, Germany.

Received: 18 February 2020 Accepted: 2 April 2021

Published online: 06 May 2021

\section{References}

1. Brignole M, Moya A, de Lange FJ, Deharo J-C, Elliott PM, Fanciulli A, Fedorowski A, Furlan R, Kenny RA, Martín A, Probst V, Reed MJ, Rice CP, Sutton R, Ungar A, van Dijk JG. Practical Instructions for the 2018 ESC Guidelines for the diagnosis and management of syncope. Eur Heart J. 2018;39:e43-80.

2. Won JGS, Tseng H-S, Yang A-H, Tang K-T, Jap T-S, Lee CH, Lin H-D, Burcus $\mathrm{N}$, Pittenger $\mathrm{G}$, Vinik A. Clinical features and morphological characterization of 10 patients with noninsulinoma pancreatogenous hypoglycaemia syndrome (NIPHS). Clin Endocrinol (Oxf). 2006;65:566-78.

3. Brignole M, Moya A, de Lange FJ, Deharo J-C, Elliott PM, Fanciulli A, Fedorowski A, Furlan R, Kenny RA, Martín A, Probst V, Reed MJ, Rice CP, 
Sutton R, Ungar A, van Dijk JG. 2018 ESC guidelines for the diagnosis and management of syncope. Eur Heart J. 2018;39:1883-948.

4. Shen W-K, Sheldon RS, Benditt DG, Cohen MI, Forman DE, Goldberger ZD, Grubb BP, Hamdan MH, Krahn AD, Link MS, Olshansky B, Raj SR, Sandhu RK, Sorajja D, Sun BC, Yancy CW. 2017 ACC/AHA/HRS guideline for the evaluation and management of patients with syncope: a Report of the American College of Cardiology/American Heart Association Task Force on Clinical Practice Guidelines and the Heart Rhythm Society, vol. 136. Quincy: National Fire Protection Assoc; 2017

5. Soteriades ES, Evans JC, Larson MG, Chen MH, Chen L, Benjamin EJ, Levy D. Incidence and prognosis of syncope. N Engl J Med. 2002;347:878-85.

6. Wagner $G$, Klinge H, Sachse MM. Ramsay Hunt syndrome. J Dtsch Dermatol Ges. 2012;10:238-44.

7. Reuber M, Elger CE. Psychogenic nonepileptic seizures: review and update. Epilepsy Behav. 2003;4:205-16.

8. Williams B, Mancia G, Spiering W, Agabiti Rosei E, Azizi M, Burnier M, Clement DL, Coca A, de Simone G, Dominiczak A, Kahan T, Mahfoud F, Redon J, Ruilope L, Zanchetti A, Kerins M, Kjeldsen SE, Kreutz R, Laurent S, Lip GYH, McManus R, Narkiewicz K, Ruschitzka F, Schmieder RE, Shlyakhto E, Tsioufis C, Aboyans V, Desormais I. 2018 ESC/ESH Guidelines for the management of arterial hypertension. Eur Heart J. 2018;39:3021-104.
9. Maintz L, Novak N. Histamine and histamine intolerance. Am J Clin Nutr. 2007;85:1185-96.

10. The Diabetes Control and Complications Trial Research Group. Adverse events and their association with treatment regimens in the diabetes control and complications trial. Diabetes Care. 1995;18:1415-27.

11. Lagi A. Syncope and Hypoglycemia. IJCM. 2011;02:129-32.

12. Lagi A, Cencetti S, Lagi F. Incidence of hypoglycaemia associated with transient loss of consciousness. A retrospective cohort study. Int I Clin Pract. 2014:68:1029-33.

13. Service FJ, Vella A. Postprandial (reactive) hypoglycemia-UpToDate. 2019. https://www.uptodate.com/contents/postprandial-reactive-hypog lycemia. [Accessed 11 August 2019].

14. Faludi G, Bendersky G, Gerber P. Functional hypoglycemia in early latent diabetes. Ann NY Acad Sci. 1968;148:868-74.

\section{Publisher's Note}

Springer Nature remains neutral with regard to jurisdictional claims in published maps and institutional affiliations.
Ready to submit your research? Choose BMC and benefit from:

- fast, convenient online submission

- thorough peer review by experienced researchers in your field

- rapid publication on acceptance

- support for research data, including large and complex data types

- gold Open Access which fosters wider collaboration and increased citations

- maximum visibility for your research: over $100 \mathrm{M}$ website views per year

At BMC, research is always in progress.

Learn more biomedcentral.com/submissions 